\title{
Allelic replacement of the streptococcal cysteine protease SpeB in a $\Delta s r v$ mutant background restores biofilm formation
}

\author{
Amity L Roberts, Robert C Holder, Sean D Reid ${ }^{*}$
}

\begin{abstract}
Background: Group A Streptococcus (GAS) is a Gram-positive human pathogen that is capable of causing a wide spectrum of human disease. Thus, the organism has evolved to colonize a number of physiologically distinct host sites. One such mechanism to aid colonization is the formation of a biofilm. We have recently shown that inactivation of the streptococcal regulator of virulence (Srv), results in a mutant strain exhibiting a significant reduction in biofilm formation. Unlike the parental strain (MGAS5005), the streptococcal cysteine protease (SpeB) is constitutively produced by the srv mutant (MGAS5005 $\Delta r v$ ) suggesting Srv contributes to the control of SpeB production. Given that SpeB is a potent protease, we hypothesized that the biofilm deficient phenotype of the srv mutant was due to the constitutive production of SpeB. In support of this hypothesis, we have previously demonstrated that treating cultures with E64, a commercially available chemical inhibitor of cysteine proteases, restored the ability of MGAS5005 $\triangle r r v$ to form biofilms. Still, it was unclear if the loss of biofilm formation by

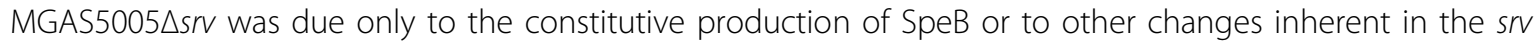
mutant strain. To address this question, we constructed a $\triangle s r v \Delta s p e B$ double mutant through allelic replacement (MGAS5005 $\triangle$ srv $\triangle$ speB) and tested its ability to form biofilms in vitro.

Findings: Allelic replacement of $s p e B$ in the srv mutant background restored the ability of this strain to form biofilms under static and continuous flow conditions. Furthermore, addition of purified SpeB to actively growing wild-type cultures significantly inhibited biofilm formation.

Conclusions: The constitutive production of SpeB by the srv mutant strain is responsible for the significant reduction of biofilm formation previously observed. The double mutant supports a model by which Srv contributes to biofilm formation and/or dispersal through regulation of speB/SpeB.
\end{abstract}

\section{Findings}

Group A Streptococcus (GAS) is a Gram-positive human pathogen that is capable of causing a wide spectrum of human disease [1-3]. Thus, the organism has evolved to colonize a number of physiologically distinct host sites. One such mechanism to aid colonization is the formation of a biofilm [4-6]. As put forth by Donlan and Costerton, a biofilm is a community of bacteria encased in an extracellular matrix [7]. The structure of this matrix may differ by bacterial species but evidence suggests the biofilm provides protection against the innate host response and therapeutic agents [8-11]. In a study

\footnotetext{
*Correspondence: sreid@wfubmc.edu

Department of Microbiology and Immunology, Wake Forest University School of Medicine, Winston-Salem, North Carolina, 27157, USA
}

of the biofilm forming ability of 219 clinical GAS isolates representing 32 serotypes, we observed considerable strain to strain variation in biofilm formation based on a crystal violet staining assay (unpublished). This variation has also been observed by others[12]. In our study, one strain named MGAS5005 formed amongst the largest biofilms we observed[13]. MGAS5005 is representative of a M1T1 clone that is globally disseminated and a leading cause of invasive infections worldwide[14-16]. This strain has been shown to have a mutation in the histidine kinase encoded by $\operatorname{cov} S$, part of the two component regulatory system CovRS (CsrRS) [17]. This mutation results in CovR repression of the cysteine protease speB $[18,19]$. Repression of SpeB is thought to contribute to the invasive phenotype of this 
clone[17,20,21]. We have recently shown that inactivation of the streptococcal regulator of virulence (Srv), a proposed transcriptional regulator with homology to the Listeria monocytogenes regulator PrfA, results in a mutant strain exhibiting a significant reduction in biofilm formation $[13,22]$. Unlike in the wild-type parental strain, the streptococcal cysteine protease (SpeB) is constitutively produced by the srv mutant suggesting Srv contributes to the control of SpeB production [23]. SpeB is capable of cleaving both host (vitronectin, fibronectin, C3b) and self (M-protein, C5a peptidase, Fba, Sda1) extracellular proteins [21,24-30]. Previous studies have shown that SpeB production leads to localized tissue damage and dissemination from the sight of infection in several murine models [31-34]. Given these previous observations, we hypothesized that the biofilm deficient phenotype of the srv mutant was due to the constitutive production of SpeB. In support of this hypothesis, we demonstrated that treating cultures with E64, a commercially available chemical inhibitor of cysteine proteases, restored the ability of the $s r v$ mutant to form biofilms [13]. Furthermore, mature SpeB was undetected in wild-type in vitro biofilms by western immunoblot analysis [13]. Still, it was unclear if the loss of biofilm formation by MGAS5005 ssrv was due only to the constitutive production of $\mathrm{SpeB}$ or to other changes inherent in the srv mutant strain. To address this question, we constructed a $\Delta s r v \Delta s p e B$ double mutant through allelic replacement (Figure 1). If our hypothesis is correct, biofilm formation would be restored in the MGAS5005 $\Delta s r v \Delta s p e B$ strain. Furthermore, one would expect that the addition of exogenous $\mathrm{SpeB}$ to a growing culture of the wild-type strain would significantly decrease biofilm formation.

The sequence located upstream of the speB ORF was amplified from MGAS5005 genomic DNA using speBsrv UP FWD (Table 1) and speBsrv UP REV (Table 1), generating an $\sim 1.1 \mathrm{~kb}$ DNA fragment. The fragment was cloned into the BsrGI-XhoI site of pFW14 [22,35,36], forming plasmid $\mathrm{pFW} 14 \Delta s p e B$-UP. Sequence located downstream of the speB ORF was amplified from MGAS5005 genomic DNA using speBsrv DOWN FWD (Table 1) and speBsrv DOWN REV (Table 1), generating an $\sim 1.1 \mathrm{~kb}$ DNA fragment. The fragment was cloned into the XmaI-AgeI site of pFW14 1 speB-UP. The resulting plasmid (pFW14 $\triangle$ speB) was transformed into NovaBlue competent cells (Novagen). Electrocompetent MGAS5005 $\Delta s r v$ cells $(200 \mu \mathrm{L})$ were incubated with pFW14 $\Delta$ speB $(2 \mu \mathrm{g}, 10 \mu \mathrm{L})$ for 10 minutes on ice. The competent cells and DNA were placed in a pre-chilled $0.2 \mathrm{~cm}$ cuvette and electroporated $(2.5 \mathrm{kV}, 25 \mu \mathrm{F}, 200$ $\Omega$ ). Electroporated cells were incubated for 10 minutes on ice. Cells were allowed to outgrow at $37^{\circ} \mathrm{C}$ with $5 \%$ $\mathrm{CO}_{2}$ for $3.5 \mathrm{~h}$ in Todd Hewitt broth supplemented with

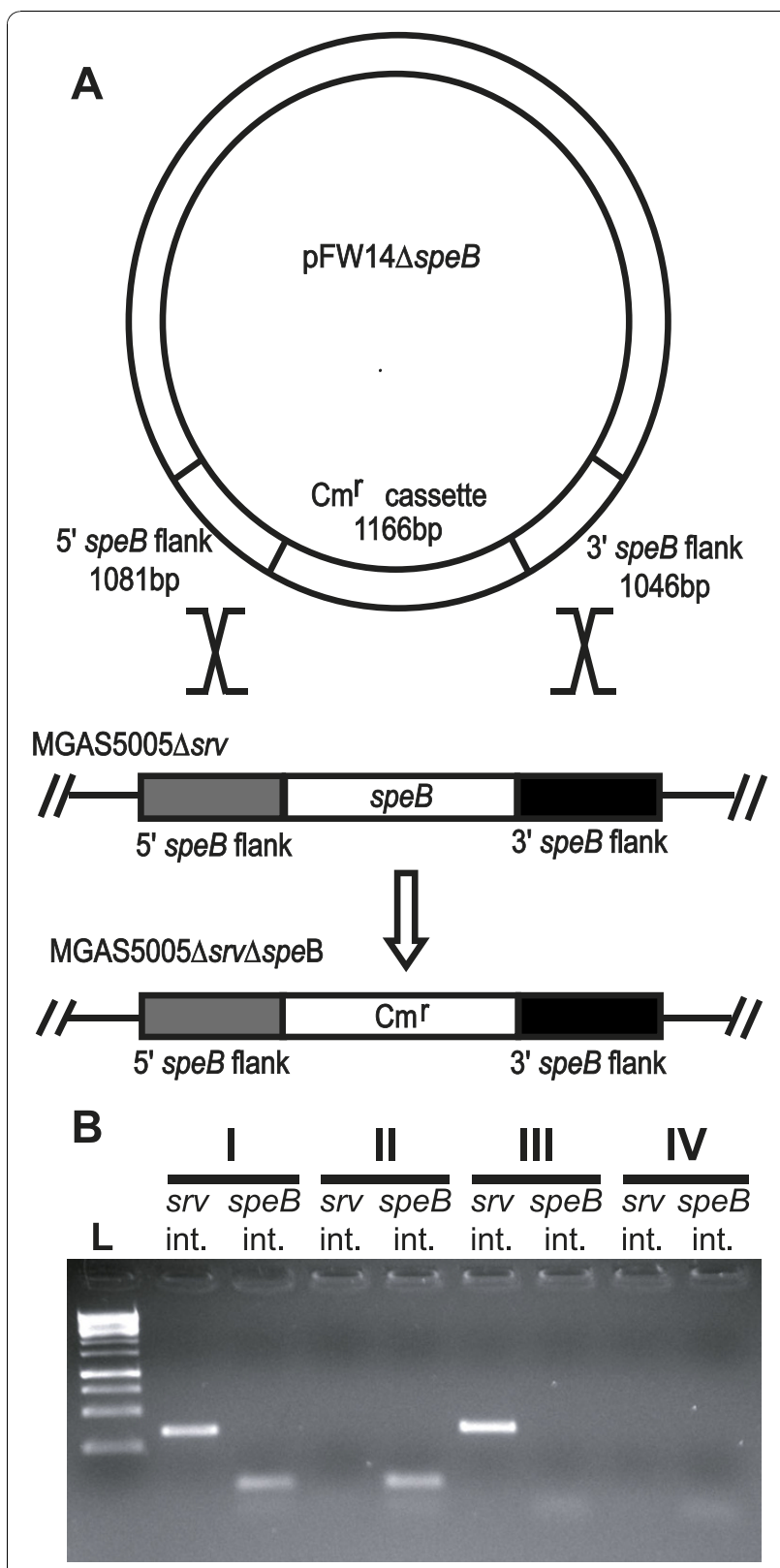

Figure 1 Construction of MGAS5005 $\Delta$ srv $\Delta$ speB. (A) speB flanking sequences were cloned upstream and downstream of the chloramphenicol resistance cassette cat $\left(\mathrm{Cm}^{r}\right)$ in pFW14. The resulting plasmid was transformed into MGAS5005 $\triangle S T$, and allelic replacement yielded MGAS5005 $\triangle$ srv $\Delta$ speB. (B) PCR of (I) MGAS5005,

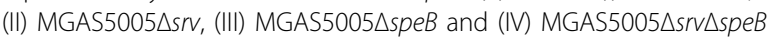
using primers $s r v$ internal FWD/REV (347 bp fragment) and internal speB FWD/REV (80 bp fragment) to verify deletion of the genes srv and speB within the MGAS5005 mutants. Ladder (L) is a $1 \mathrm{kB}$ ladder.

2\% Yeast extract (THY) (Becton, Dickson, Company). Selection for MGAS5005 $\Delta$ srv $\Delta$ speB occurred on THY agar supplemented with chloramphenicol $(5 \mu \mathrm{g} / \mathrm{mL})$ (Sigma) and incubated at $37^{\circ} \mathrm{C}$ with $5 \% \mathrm{CO}_{2}$ for 48 hours. The speB deletion was verified in chloramphenicol resistant transformants using PCR and restriction 
Table 1 Primers and probes used in this study

\begin{tabular}{ll}
\hline Primer or probe & Sequence \\
\hline speB internal FWD & 5'-TCAACATGCAGCTACAGGATGTG-3' \\
speB internal REV & 5'-TCAACCCTTGTTAGGGTAATTATGATA-3' \\
internal srv FWD & 5'-GCATTGTGAAACAGAGTGTTCTTCAAAATATGG-3' \\
internal srv REV & 5'-TAGTTCTTCGCCAAATAGGGTCATTAAGTC-3' \\
prsA 309AA FWD & 5'-GCGACAGTCGTGACCTTATCAG-3' \\
prsA 309AA REV & 5'-CTGACAGTGATGGTGTCTCCTTC-3 \\
prsA 309AA Probe & 5'-CATCACACAACAACACCAAACTCGTC-3' \\
speBsrv UP FWD & 5' ATATATATTGTACACGATAATAGGTTGCCT \\
& AGTGAG-3' \\
speBsrv UP REV & 5'-ATATATATCTCGAGGCTAAAAGACTTAATAATC \\
& TGACACC-3' \\
speBsrv DOWN FWD & 5'-ATATATATCCCGGGCAGTATACTACCAAGGTGT \\
speBsrv DOWN REV & CGG-3' \\
gyrA FWD & 5'-CGATATATACCGGTCGCCAGCGTTACCACTC-3' \\
gyrA REV & 5'-TTATCACGTTCCAAACCAGTCAA-3' \\
gyrA Probe & 5'-CGACGCAAACGCATATCCAAAATAGCTTGE-3' \\
\hline
\end{tabular}

digestion. A PCR utilizing internal $s r v$ and internal speB primers (Table 1) was performed on genomic DNA of MGAS5005 wild-type (I), MGAS5005 $\Delta s r v$ (II), MGAS5005 $\Delta s p e B$ (III) and MGAS5005 $\Delta s r v \Delta s p e B$ (IV) (Figure 1B) to validate deletion of either srv or $s p e B$ or both within the indicated mutants.

To verify that speB mRNA was not produced by MGAS5005 $\Delta r v \Delta s p e B$, total RNA was isolated from MGAS5005 (control) and MGAS5005 $\Delta r v \Delta s p e B$ and subjected to TaqMan real-time reverse transcriptase PCR (RT-PCR) analysis [37,38]. Results indicated that transcript was not produced for either srv or speB (data not shown) in the MGAS5005 $\Delta r v \Delta s p e B$ strain. Transcript of $p r s A$, a gene located immediately downstream of speB, was $\sim 3$ fold higher in MGAS5005 $\Delta r v \Delta$ speB than MGAS5005, indicating that transcription of downstream genes was not disrupted. It should be noted that MGAS5005 $\Delta s r v[22]$ and MGAS5005 $\Delta$ speB have previously been shown to be free of detectable polar effects $[31,34,39]$. Also, Srv and SpeB have both been shown to be produced by MGAS5005 [22,23].

To examine biofilm formation, MGAS5005, MGAS5005 $\Delta s r v$, MGAS5005 speB [31,34,39] and MGAS5005 $\Delta$ srv $\triangle$ spe $B$ cultures were grown under static conditions $(0.5 \mathrm{~h}-48 \mathrm{~h})$; biofilm production was measured through crystal violet $(\mathrm{CV})$ staining as previously described [13] (Figure 2). Inactivation of speB in the srv mutant background restored biofilm formation to near wild-type levels after $24 \mathrm{~h}$ (Figure 2A). Inactivation of speB in the MGAS5005 wild-type background does not

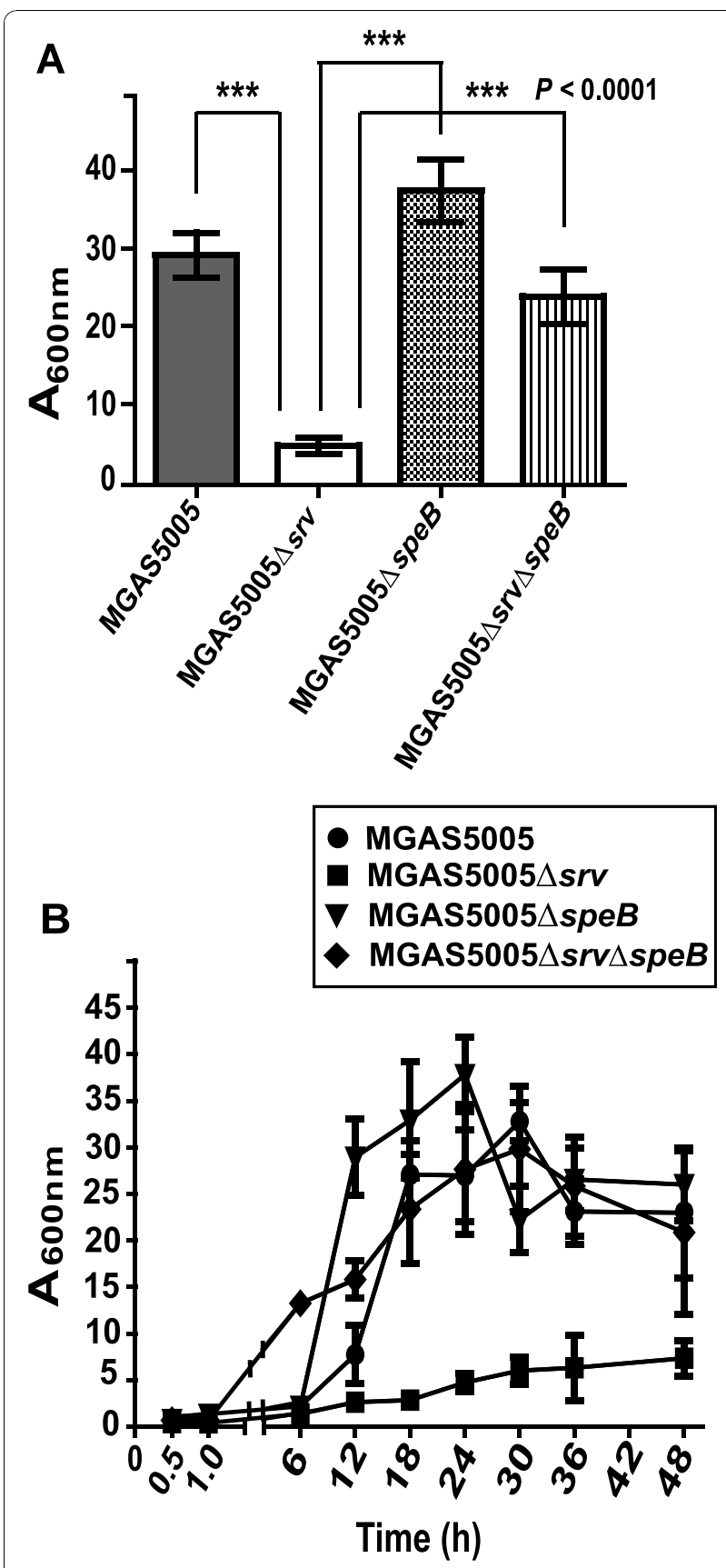

Figure 2 Static crystal violet assays for the measurement of in vitro biofilm formation. MGAS5005, MGAS5005 $\triangle \mathrm{Sr}$,

MGAS5005 $\triangle$ speB and MGAS5005 $\triangle$ srv $\triangle$ speB were grown in 6-well tissue culture treated polystyrene plates for $24 \mathrm{~h}(\mathrm{~A})$, stained with crystal violet, and solubilized with ethanol. Each reported value for the CV assay is an average of at least 6 replicates and is adjusted by the dilution factor required to obtain a spectrophometric reading $\left(A_{600} \mathrm{~nm}\right)(P \leq 0.0001$, unpaired t-test). (B) Biofilm formation for each strain over time is shown out to $48 \mathrm{~h}$. 


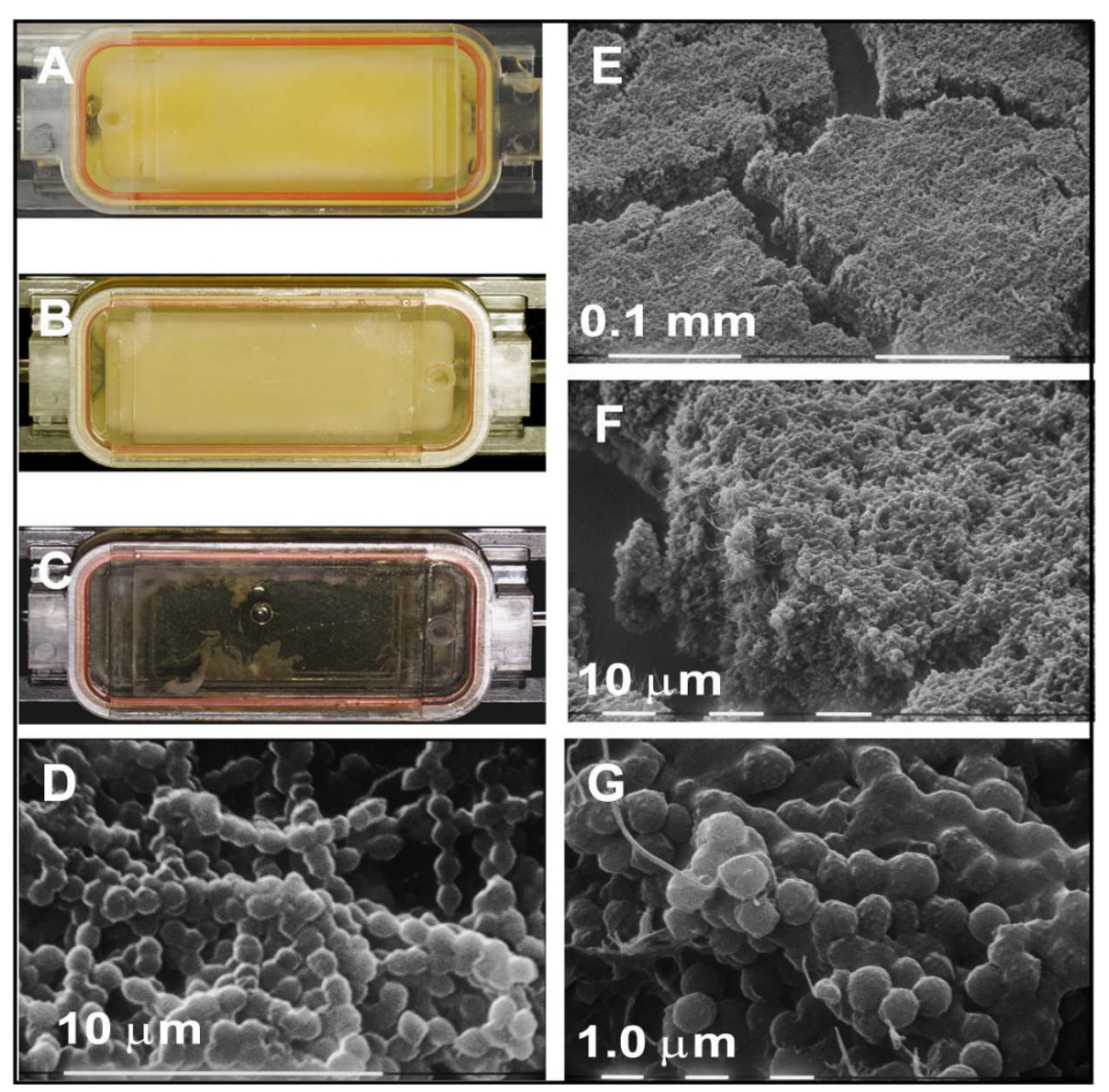

Figure 3 MGAS5005 $\Delta$ srv $\Delta$ speB biofilm formation under continuous flow conditions. (A-C) Representative flow cell chambers containing 24

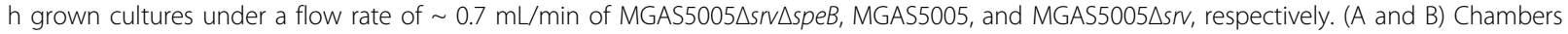
inoculated with (A) MGAS5005 $\Delta s r \Delta s p e B$ or (B) MGAS5005 were filled with dense viscous material indicative of GAS biofilms. (C) MGAS5005 $\Delta s r v$

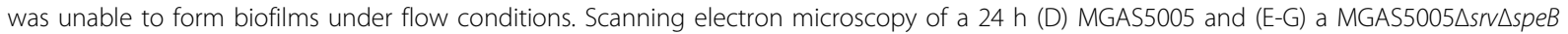
continuous flow biofilm clearly depicts chains of cocci organized into a 3-dimensional structure encased in a matrix-like material.

alter biofilm formation (Figure 2A). MGAS5005 $\Delta s r v \Delta$ $s p e B$ formed significantly more biofilm than that of MGAS5005 $\Delta$ srv ( $P \leq 0.001$, unpaired student's t-test). Over time, biofilm formation of MGAS5005 $\Delta$ srv $\Delta$ speB closely resembled what we have previously reported for MGAS5005 with maximal formation occurring between $24 \mathrm{~h}$ and $30 \mathrm{~h}$ with a subtle decline in CV staining thereafter (Figure 2B) [13]. Planktonic growth of MGAS5005, MGAS5005 srv, MGAS5005 $\Delta s p e B$, and MGAS5005 $\Delta r v \Delta s p e B$ indicated that there was no growth defect of the mutant strains compared to the wild-type as equivalent bacterial loads were recovered over time (e.g. AVG $8.32 \pm 0.72 \log 10 \mathrm{CFU} / \mathrm{mL} 7 \mathrm{~h}$ post-growth initiation).

Studies have shown that hydrodynamic shear forces are often needed for biofilm formation as these conditions are comparable to that of the host environment [40-42]. MGAS5005 $\Delta r v$ was unable to form a biofilm under continuous flow conditions [13]. To verify that the restored biofilm phenotype observed for MGAS5005 $\Delta s r v \Delta s p e B$ was maintained under continuous flow, MGAS5005 $\Delta r v \Delta s p e B$ was grown in a flow cell chamber under a flow rate of $\sim 0.7 \mathrm{~mL} / \mathrm{min}$ for $24 \mathrm{~h}$ as previously described [13]. After $24 \mathrm{~h}$, the flow chamber was completely filled with a viscous substance (Figure 3A) comparable to flow chamber grown wild-type MGAS5005 (Figure 3B). Once again, MGAS5005 $\Delta r v$ v failed to attach and form a biofilm under these conditions (Figure 3C). Electron microscopy revealed a dense population of MGAS5005 ssrv $\Delta s p e B$ organized in a three-dimensional structure (Figure $3 \mathrm{E}-\mathrm{G}$ ). Visually, this structure is equivalent to the MGAS5005 biofilms we have observed (Figure 3D) [13]. Higher magnification revealed chains of MGAS5005 $\Delta s r v \Delta s e B$ (Figure 3G) which appeared to be coated in a matrix material comparable to what has been seen in MGAS5005 biofilms 


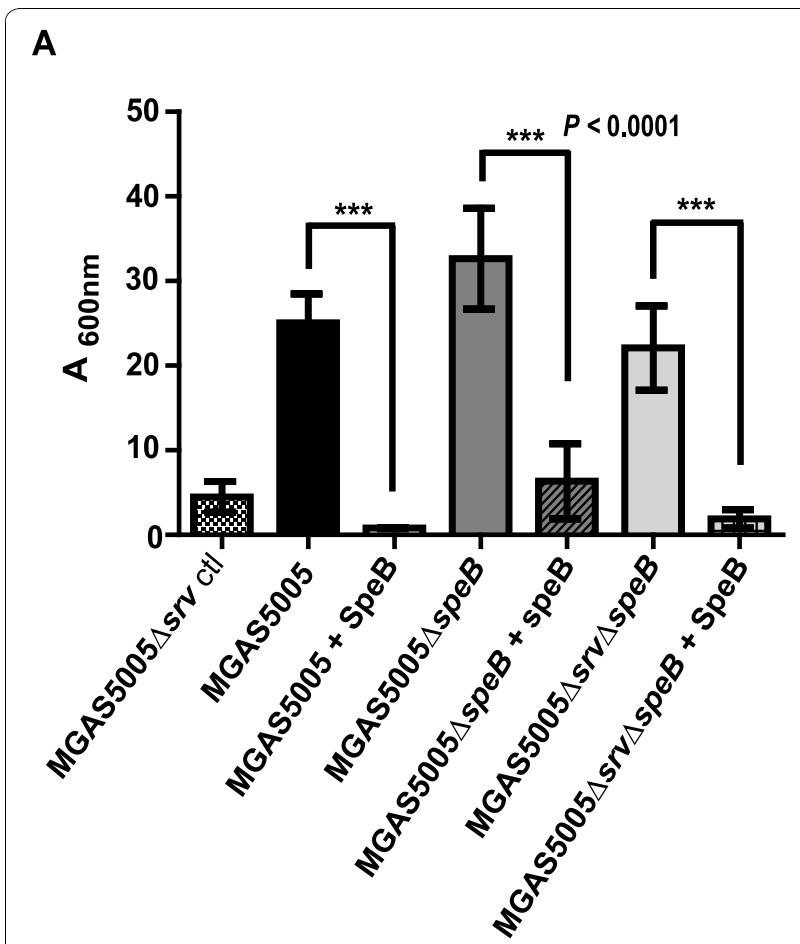

Figure 4 Addition of purified active SpeB inhibits biofilm formation. MGAS5005, MGAS5005 $\triangle$ speB and MGAS5005 $\triangle$ srv $\triangle$ speB were either untreated or treated with $1 \mu \mathrm{g} / \mathrm{mL}$ of purified SpeB (Toxin Technology, Inc., Sarasota, FL) 3 times at time 0, 6 h, and 12 h. Biofilm was measured at $18 \mathrm{~h}$ using CV staining as previously discussed. The level of reduction in biofilm formation was statistically significant $\left(\left({ }^{* * *}\right) P<0.0001\right)$ compared to the untreated samples. MGAS5005 $\triangle s r v$, with constitutive production of SpeB, is presented for comparison.

(Figure 3D) [13]. Thus, MGAS5005 $\Delta r r v \Delta s p e B$ can form a biofilm under continuous flow conditions.

To prove that SpeB alone is capable of disrupting GAS biofilm formation, we added purified active SpeB (Toxin Technology, Inc., Sarasota, FL)(final concentration $1 \mu \mathrm{g} /$ $\mathrm{mL}) 3$ times over the course of static biofilm development $(0,6 \mathrm{~h}$, and $12 \mathrm{~h})$. CV staining was performed on treated and untreated samples at $18 \mathrm{~h}$ postseeding (Figure 4). SpeB addition resulted in a significant decrease in measurable biofilm of all treated strains to levels comparable to MGAS5005 $\Delta$ srv (Figure 4).

Taken together, the data indicate that the biofilm deficient phenotype of MGAS5005 $\Delta s r v$ is due to the constitutive production of mature SpeB. Inactivation of speB in the MGAS5005 srv background restored biofilm formation to wild-type levels. Complementation of MGAS5005 $\Delta$ srv $\Delta$ speB through the addition of exogenous SpeB significantly reduced biofilm formation to MGAS5005 ssrv levels. These results support a model in which the Srv mediated control of SpeB production regulates GAS biofilm formation (Figure 5). Following initial exposure and attachment, our model would predict Srv-based negative regulation of SpeB production. This state would allow biofilm formation and colonization. Likewise, an opposite state would be predicted in which SpeB production is upregulated allowing biofilm dispersal and dissemination/transmission of GAS. We hypothesize an equilibrium exists between these two states such that controlled levels of SpeB may be produced to facilitate transmission while preventing complete biofilm disruption. For clarity, it is important to point out that our work was done in the MGAS5005 background, a background which contains a mutation in $\operatorname{cov} S$, which has been shown to be involved in invasive disease and is characterized by an invasive transcriptome profile[14,15]. Recently, Hollands et al. have shown in a separate M1T1 strain (5448) that mutation of $\operatorname{cov} S$ (obtained following passage through an animal model) resulted in a strain with decreased biofilm formation due to increased capsule production[20]. They show that 5448 formed more biofilm than the 5448 covS mutant[20]. Thus, our future work is directed at studying the effects of mutation of $s r v$ in a covS + M1T1 background (as well as in other serotypes) to understand the role of Srv in biofilm formation and GAS disease.

\section{Exposure -> Attachment Biofilm formation
Srv + / SpeB - Colonization $\quad \begin{gathered}\text { Biofilm disruption-> } \\ \text { Dissemination } \\ \text { Transmission/ } \\ \text { Srv - / SpeB + }\end{gathered}$}

Figure 5 Hypothetical model of Srv/SpeB mediated GAS biofilm formation and dispersal. Following GAS exposure, Srv-mediated negative regulation of SpeB production would allow biofilm formation and colonization. As of yet unidentified environmental signals may reverse this control, promoting SpeB production and subsequent biofilm dispersal in order to facilitate dissemination/transmission of the organism. We hypothesize that this cycle is likely held in equilibrium such that controlled amounts of SpeB may be produced to allow dissemination without complete disruption of the GAS biofilm. 


\section{Acknowledgements}

This work was supported by Public Health Service Grant R01A1063453 from the National Institutes of Health to SDR. We would like to thank S. Lukomski for graciously providing us with the MGAS5005 $\triangle$ speB single mutant.

\section{Authors' contributions}

ALR participated in the design of the study, conducted in vitro experiments, and drafted manuscript. RCH designed and developed MGAS5005 $\triangle s r v s p e B$ mutant and critically analyzed manuscript. SDR participated in the design of the study and helped to draft the manuscript. All authors read and approved of the final manuscript.

\section{Competing interests}

The authors declare that they have no competing interests.

Received: 5 July 2010 Accepted: 4 November 2010 Published: 4 November 2010

\section{References}

1. Cunningham MW: Pathogenesis of group A streptococcal infections. Clin Microbiol Rev 2000, 13:470-511.

2. Bisno AL, Stevens DL: Streptococcal infections of skin and soft tissues. $N$ Engl J Med 1996, 334:240-5.

3. Davies HD, McGeer A, Schwartz B, Green $K$, Cann D, Simor AE, Low DE: Invasive group A streptococcal infections in Ontario, Canada. Ontario Group A Streptococcal Study Group. N Engl J Med 1996, 335:547-54.

4. Costerton JW, Cheng KJ, Geesey GG, Ladd TI, Nickel JC, Dasgupta M, Marrie TJ: Bacterial biofilms in nature and disease. Annu Rev Microbiol 1987, 41:435-64.

5. Costerton JW, Lewandowski Z, Caldwell DE, Korber DR, Lappin-Scott HM: Microbial biofilms. Annu Rev Microbiol 1995, 49:711-45

6. Dunne WM Jr: Bacterial adhesion: seen any good biofilms lately? Clin Microbiol Rev 2002, 15:155-66.

7. Donlan RM, Costerton JW: Biofilms: survival mechanisms of clinically relevant microorganisms. Clin Microbiol Rev 2002, 15:167-93.

8. Lewis K: Persister cells, dormancy and infectious disease. Nat Rev Microbiol 2007, 5:48-56.

9. Stewart PS, Costerton JW: Antibiotic resistance of bacteria in biofilms. Lancet 2001, 358:135-8

10. Fux CA, Costerton JW, Stewart PS, Stoodley P: Survival strategies of infectious biofilms. Trends Microbiol 2005, 13:34-40.

11. Costerton JW, Stewart PS, Greenberg EP: Bacterial biofilms: a common cause of persistent infections. Science 1999, 284:1318-22.

12. Baldassarri $L$, Creti R, Recchia S, Imperi M, Facinelli B, Giovanetti $E$, Pataracchia M, Alfarone G, Orefici G: Therapeutic failures of antibiotics used to treat macrolide-susceptible Streptococcus pyogenes infections may be due to biofilm formation. J Clin Microbiol 2006, 44:2721-7.

13. Doern CD, Roberts AL, Hong W, Nelson J, Lukomski S, Swords WE, Reid SD: Biofilm formation by group A Streptococcus: a role for the streptococcal regulator of virulence (Srv) and streptococcal cysteine protease (SpeB). Microbiology 2009, 155:46-52.

14. Sumby P, Whitney AR, Graviss EA, DeLeo FR, Musser JM: Genome-wide analysis of group a streptococci reveals a mutation that modulates global phenotype and disease specificity. PLOS Pathog 2006, 2:e5.

15. Musser JM, Krause RM: The Revival of Group A Streptococcal Diseases, with a Commentary on Staphylococcal Toxic Shock Syndrome. Academic Press; 1998.

16. Reid SD, Hoe NP, Smoot LM, Musser JM: Group A Streptococcus: allelic variation, population genetics, and host-pathogen interactions. J Clin Invest 2001, 107:393-9.

17. Sumby P, Porcella SF, Madrigal AG, Barbian KD, Virtaneva K, Ricklefs SM, Sturdevant DE, Graham MR, Vuopio-Varkila J, Hoe NP, et al: Evolutionary origin and emergence of a highly successful clone of serotype M1 group a Streptococcus involved multiple horizontal gene transfer events. J Infect Dis 2005, 192:771-82.

18. Trevino J, Perez N, Ramirez-Pena E, Liu Z, Shelburne SA, Musser JM, Sumby P: CovS simultaneously activates and inhibits the CovR-mediated repression of distinct subsets of group A Streptococcus virulence factorencoding genes. Infect Immun 2009, 77:3141-9.

19. Heath A, DiRita VJ, Barg NL, Engleberg NC: A two-component regulatory system, CsrR-CsrS, represses expression of three Streptococcus pyogenes virulence factors, hyaluronic acid capsule, streptolysin $\mathrm{S}$, and pyrogenic exotoxin B. Infect Immun 1999, 67:5298-305

20. Hollands A, Pence MA, Timmer AM, Osvath SR, Turnbull L, Whitchurch CB, Walker MJ, Nizet V: Genetic switch to hypervirulence reduces colonization phenotypes of the globally disseminated group A Streptococcus M1T1 clone. J Infect Dis 2010, 202:11-9.

21. Walker MJ, Hollands A, Sanderson-Smith ML, Cole JN, Kirk JK, Henningham A, McArthur JD, Dinkla K, Aziz RK, Kansal RG, et al: DNase Sda1 provides selection pressure for a switch to invasive group $A$ streptococcal infection. Nat Med 2007, 13:981-5.

22. Reid SD, Montgomery AG, Musser JM: Identification of srv, a PrfA-like regulator of group $A$ streptococcus that influences virulence. Infect Immun 2004, 72:1799-803.

23. Reid SD, Chaussee MS, Doern CD, Chaussee MA, Montgomery AG, Sturdevant DE, Musser JM: Inactivation of the group A Streptococcus regulator srv results in chromosome wide reduction of transcript levels, and changes in extracellular levels of Sic and SpeB. FEMS Immunol Med Microbiol 2006, 48:283-92

24. Berge A, Bjorck L: Streptococcal cysteine proteinase releases biologically active fragments of streptococcal surface proteins. J Biol Chem 1995, 270:9862-7.

25. Ji Y, MCLandsborough L, Kondagunta A, Cleary PP: C5a peptidase alters clearance and trafficking of group A streptococci by infected mice. Infect Immun 1996, 64:503-10.

26. Kansal RG, Nizet V, Jeng A, Chuang WJ, Kotb M: Selective modulation of superantigen-induced responses by streptococcal cysteine protease. J Infect Dis 2003, 187:398-407.

27. Kapur V, Majesky MW, Li LL, Black RA, Musser JM: Cleavage of interleukin 1 beta (IL-1 beta) precursor to produce active IL-1 beta by a conserved extracellular cysteine protease from Streptococcus pyogenes. Proc Natl Acad Sci USA 1993, 90:7676-80.

28. Raeder R, Woischnik M, Podbielski A, Boyle MD: A secreted streptococcal cysteine protease can cleave a surface-expressed M1 protein and alter the immunoglobulin binding properties. Res Microbiol 1998, 149:539-48.

29. Terao Y, Mori Y, Yamaguchi M, Shimizu Y, Ooe K, Hamada S, Kawabata S: Group A streptococcal cysteine protease degrades C3 (C3b) and contributes to evasion of innate immunity. J Biol Chem 2008, 283:6253-60.

30. Wei L, Pandiripally V, Gregory E, Clymer M, Cue D: Impact of the SpeB protease on binding of the complement regulatory proteins factor $\mathrm{H}$ and factor $\mathrm{H}$-like protein 1 by Streptococcus pyogenes. Infect Immun 2005, 73:2040-50.

31. Lukomski S, Burns EH Jr, Wyde PR, Podbielski A, Rurangirwa J, MoorePoveda DK, Musser JM: Genetic inactivation of an extracellular cysteine protease (SpeB) expressed by Streptococcus pyogenes decreases resistance to phagocytosis and dissemination to organs. Infect Immun 1998, 66:771-6.

32. Kuo CF, Wu JJ, Lin KY, Tsai PJ, Lee SC, Jin YT, Lei HY, Lin YS: Role of streptococcal pyrogenic exotoxin B in the mouse model of group $A$ streptococcal infection. Infect Immun 1998, 66:3931-5.

33. Tamura F, Nakagawa $R$, Akuta $T$, Okamoto $S$, Hamada S, Maeda H, Kawabata S, Akaike T: Proapoptotic effect of proteolytic activation of matrix metalloproteinases by Streptococcus pyogenes thiol proteinase (Streptococcus pyrogenic exotoxin B). Infect Immun 2004, 72:4836-47.

34. Lukomski S, Sreevatsan S, Amberg C, Reichardt W, Woischnik M, Podbielski A, Musser JM: Inactivation of Streptococcus pyogenes extracellular cysteine protease significantly decreases mouse lethality of serotype M3 and M49 strains. J Clin Invest 1997, 99:2574-80.

35. Lukomski S, Nakashima K, Abdi I, Cipriano VJ, Ireland RM, Reid SD, Adams GG, Musser JM: Identification and characterization of the scl gene encoding a group A Streptococcus extracellular protein virulence factor with similarity to human collagen. Infect Immun 2000, 68:6542-53.

36. Podbielski A, Spellerberg B, Woischnik M, Pohl B, Lutticken R: Novel series of plasmid vectors for gene inactivation and expression analysis in group A streptococci (GAS). Gene 1996, 177:137-47.

37. Chaussee MS, Watson RO, Smoot JC, Musser JM: Identification of Rggregulated exoproteins of Streptococcus pyogenes. Infect Immun 2001 69:822-31. 
38. Reid SD, Green NM, Sylva GL, Voyich JM, Stenseth ET, DeLeo FR, Palzkill T, Low DE, Hill HR, Musser JM: Postgenomic analysis of four novel antigens of group a streptococcus: growth phase-dependent gene transcription and human serologic response. J Bacteriol 2002, 184:6316-24.

39. Lukomski S, Montgomery CA, Rurangirwa J, Geske RS, Barrish JP, Adams GJ, Musser JM: Extracellular cysteine protease produced by Streptococcus pyogenes participates in the pathogenesis of invasive skin infection and dissemination in mice. Infect Immun 1999, 67:1779-88.

40. Lappin-Scott HM, Bass C: Biofilm formation: attachment, growth, and detachment of microbes from surfaces. Am J Infect Control 2001, 29:250-1.

41. Purevdorj B, Costerton JW, Stoodley P: Influence of hydrodynamics and cell signaling on the structure and behavior of Pseudomonas aeruginosa biofilms. Appl Environ Microbiol 2002, 68:4457-64.

42. Stoodley P, Wilson S, Hall-Stoodley L, Boyle JD, Lappin-Scott HM, Costerton JW: Growth and detachment of cell clusters from mature mixed-species biofilms. Appl Environ Microbiol 2001, 67:5608-13.

doi:10.1186/1756-0500-3-281

Cite this article as: Roberts et al:: Allelic replacement of the

streptococcal cysteine protease SpeB in a $\Delta s r v$ mutant background restores biofilm formation. BMC Research Notes 2010 3:281.

\section{Submit your next manuscript to BioMed Central} and take full advantage of:

- Convenient online submission

- Thorough peer review

- No space constraints or color figure charges

- Immediate publication on acceptance

- Inclusion in PubMed, CAS, Scopus and Google Scholar

- Research which is freely available for redistribution

Submit your manuscript at www.biomedcentral.com/submit
Ciomed Central 